\title{
O direito a terra e as crianças kaiowá e guarani da Aldeia Pakurity, MS
}

\author{
The right to the land and the kaiowa and guarani childreen \\ of the indigenous Village of Pakurity, MS
}

\author{
Sônia Rocha Lucas ${ }^{1}$ \\ Antonio Hilario Aguilera Urquiza ${ }^{1}$
}

DOI: http://dx.doi.org/10.20435/tellus.v18i35.472

\begin{abstract}
Resumo: O presente texto está inserido em uma pesquisa de mestrado em andamento, no Programa de Pós-Graduação em Antropologia da UFGD. Voltase a uma pesquisa bibliográfica e contempla elementos preliminares de um primeiro trabalho de campo realizado na aldeia Pakurity. O objetivo é trazer à discussão o direito à terra em sua forma legal e de identificar a atual situação fundiária da aldeia, bem como descrever como se dá o processo de demarcação das terras e sinalizar os limites do território tradicionalmente ocupado pelos indígenas da tekoha Pakurity. O aporte teórico-metodológico é a pesquisa bibliográfica e o trabalho de campo, utilizado na própria Antropologia, e a partir disto, ainda contamos com a observação participante, diário de campo e outras formas de registros. Os autores que dão sustentação teórica são: Brand (1993; 1997), Cavalcante (2013), Crespe (2009), Pereira (2002; 2007; 2010), Eloy Amado (2015 ) e Cunha (1992 ). Os povos indígenas e a permanência em sua terra tradicional configuram-se como um direito originário e, para tanto, esta é submetida aos procedimentos administrativos de demarcação de terras indígenas estabelecidos no Decreto n. 1775/96. Trazer a forma como se dá todo esse processo é confirmar que a demarcação das terras indígenas é um ato que, de forma indireta, beneficia a sociedade de forma geral, pois garante a construção de uma sociedade pluriétnica e multicultural.
\end{abstract}

Palavras-chave: direito a terra; crianças indígenas; aldeia Pakurity.

Abstract: This text is part of the master's research project in progress, of the Anthropology Postgraduate Program at UFGD. It is a bibliographic research and includes preliminary elements of a first made fieldwork in the indigenous village of Pakurity. The objective is bring to discussion the right to the land

${ }^{1}$ Universidade Federal de Mato Grosso do Sul (UFMS), Campo Grande, Mato Grosso do Sul, Brasil. 
in general and identify the present landholding situation, as well as describe how works the demarcation of lands and mark the limits of the traditionally occupied territory by the indigenous people of Tekoha Pakurity. The theoretical-methodological is based in bibliographic research and filed work, used in the Anthropology, and the participant observation, field diary and other forms of record. The authors used for theoretical support are: $(1993,1997)$, Cavalcante (2013), Crespe (2009), Pereira (2002, 2007 e 2010), Eloy Amado (2015) and Cunha (1992). The indigenous people and the permanence in their traditional land are configured as a primary law, for this purpose, it is submitted to administrative procedures of demarcation of indigenous lands established by decree $1775 / 96$. Bring up the way how this whole process works confirms that the indigenous land demarcation is an act that in some way benefits the society in general, because it ensures the construction of a pluri-ethnic and multicultural society.

Keywords: the right to land; indigenous children; village Of Pakurity.

\section{INTRODUÇÃO}

Fruto do resultado parcial de uma pesquisa para o programa de PósGraduação em Antropologia (UFGD), nível Mestrado, esta consiste em estudar as crianças indígenas, como vivem e percebem a situação de acampamento, tendo como referência a história dos indígenas Kaiowá e Guarani² ${ }^{2}$ e a realidade do acampamento Pakurity situado no município de Dourados, MS.

Podemos dizer, primeiramente, que a relevância desta pesquisa é baseada no Artigo 231 da Constituição Federal de 1988, que reconhece o direito dos povos indígenas a possuírem seus costumes, línguas, religiões e organização social distintas da sociedade nacional. Apesar das garantias constitucionais, salientamos, no entanto, o fato de Mato Grosso do Sul se apresentar, nos últimos anos, como o Estado de maior violência contra os povos indígenas no país (CONSELHO INDIGENISTA MISSIONÁRIO [CIMI], 2014). Sendo assim, tem um dos quadros mais graves de violação de direitos humanos dos povos indígenas, sendo um dos principais indicadores a baixíssima taxa de demarcação de suas terras tradicionais. Segundo o relatório de Violência Contra os Povos Indígenas em Mato Grosso do

\footnotetext{
${ }^{2}$ Utilizamos o termo Kaiowá e Guarani para nos referirmos aos Guarani Kaiowá e aos Guarani Ñandeva. Salientando que possuem diferenças, apesar de apresentarem proximidade cultural, sociológica, linguística e territorial.
} 
Sul, publicado pelo CIMI (2010, p. 16), "no ano de 2003 a 2010 houve no Mato Grosso do Sul 250 assassinatos de indígenas, enquanto no restante do Brasil, neste mesmo período, foram registrados 202". Já no ano de 2014 foram 25 vítimas indígenas só em Mato Grosso do Sul (CIMI, 2014, p. 76).

De acordo com os resultados do Censo Demográfico do Instituto Brasileiro de Geografia e Estatística (IBGE, 2010), a população brasileira soma 190.755.799 milhões de pessoas, e 817,9 mil pessoas se declararam indígenas contabilizados pelo quesito cor ou raça. Somando todos os que não se declaram nesse quesito (raça e cor), mas se declaram indígenas e são contabilizados dentro das terras indígenas, o total de população residente no território nacional passa para 896,9 mil pessoas, distribuídas em 305 diferentes etnias e com o registro de 274 línguas indígenas no país. Desses, 36,2\% residem na área urbana e 63,8\% na área rural, sendo 517,383 mil residindo em Terras Indígenas e 379,534 mil vivendo fora delas. Em se tratando de porcentagem, o conjunto de indígenas que residiam nas terras indígenas é de 57,7\% e 42,3\% fora delas. Esse dado nos mostra que quase a metade da população indígena do Brasil está vivendo fora das Terras Indígenas, o que demonstra a necessidade e a urgência de que o Estado possa garantir aos povos indígenas seus direitos assegurados pela Constituição Federal, principalmente ao se tratar do direito a posse de seus territórios.

Na região Centro-Oeste, há 143,432 mil indígenas, e 72,5\% residem nas Terras Indígenas. Em Mato Grosso do Sul, encontra-se a maior população indígena da região Centro-Oeste e a segunda maior do país com 77.025 indígenas, e 79\% de sua população vive em Terras Indígenas. Esse dado não significa que a questão da propriedade da terra é um assunto resolvido no estado, pois, em Mato Grosso do Sul, o tema das comunidades indígenas e seus territórios tem sido objeto de grande polêmica, tendo em vista a realidade dos últimos anos, de constante conflito fundiário entre índios e proprietários rurais, levando o estado, há anos, a possuir a liderança no ranking nacional de violência contra os povos indígenas.

Analisar os dados apresentados é de suma importância, mas se faz necessário olhar para a dura realidade enfrentada pelos indígenas do estado do Mato Grosso do Sul como parte de uma situação histórica. Nesse sentido, torna-se necessário fazer um breve histórico dos povos indígenas Kaiowá e Guarani do Mato Grosso do Sul e como se deu o processo que culminou na perda territorial. 


\section{BREVE HISTÓRICO DO ESBULHO}

Com a Guerra do Paraguai (final do século XIX) e durante todo o período histórico da Primeira República (meados do século XX), notamos episódios que acarretaram grandes modificações no cenário nacional e que, mais tarde, culminariam na atual situação de "confinamento" dos povos indígenas (BRAND, 1993; 1997) ${ }^{3}$ e situações que resultaram no esbulho de seus tekoha ${ }^{4}$.

A Colônia Agrícola Nacional de Dourados (CAND) foi outro fator de grande impacto. Criada em 1943, como política de ocupação dessa região, trouxe para o Estado muitos colonos com a finalidade de povoar o território (colonização), mas bem sabemos que esses territórios estavam ocupados por povos indígenas, especialmente os Guarani. Podemos notar nas palavras de Brand o quanto a CAND interferiu nesse cenário da perda das terras indígenas.

A implantação da Colônia em área de aldeias Kaiowá marcou o início de uma longa e difícil luta dos índios pela manutenção e recuperação de nossas terras. Negavamos em deixar as terras, que foram vendidas pelo governo a colonos. Estes, por sua vez, buscavam constantemente obter a expulsão dos índios, através de ações na justiça, ou através de meios mais escursos. (BRAND, 1997, p. 78).

Assim feito, abriu-se espaço para a concessão de títulos públicos a particulares com o intuito de ocuparem os "espaços vazios", chamados de "terras devolutas", em nome do desenvolvimento nacional. Bem sabemos que esses espaços não eram propriamente "vazios", mas de uso e permanência dos indígenas. E para Brand (1997, p. 85), "o problema das terras indígenas, usurpadas pela Colônia Agrícola Nacional de Dourados, a partir de 1943, permanece sem solução até a presente data".

Com a intenção de liberar as terras para os novos colonos, nos anos de 1915 a 1928 foram criadas as oito reservas ${ }^{5}$ indígenas no sul do estado para abrigar os

\footnotetext{
${ }^{3}$ Conforme estudos de Brand $(1993 ; 1997)$, entendemos por confinamento compulsório a transferência sistemática e forçada da população das diversas aldeias Kaiowá e Guarani tradicionais para dentro das oito Reservas demarcadas pelo governo entre 1915 e 1928.

${ }^{4}$ Lugar físico e espiritual - terra, mato, campo, águas, animais, plantas, remédios etc. - onde se realiza o teko, o "modo de ser", o estado de vida guarani. Engloba a efetivação de relações sociais de grupos macro familiares que vivem e se relacionam em um espaço físico determinado (conforme CAVALCANTE, 2013; e http://pib.socioambiental.org/pt/povo/guarani-nandeva/1298, acesso em: 22 nov. 2013).

${ }^{5}$ As oito reservas são: Amambai, Dourados, Caarapó, Porto Lindo, Taquaperi, Sassoró, Limão Verde e Pirajuí (CAVALCANTE, 2013, p. 84).
} 
indígenas das etnias Kaiowá e Guarani. Cabe ressaltar que, em nenhum momento, foi pensada ou respeitada a diferença étnica de seus grupos e o direito inalienável a seus territórios tradicionais, situação que acarretou e ainda acarreta um grande conflito interno. Diante desse fato, ou seja, com a criação dessas reservas, a situação do território e a própria cosmologia dos Kaiowá e Guarani ficaram comprometidas, tendo em vista a importância da terra para o modo de viver em seus tekoha. Tal importância é destacada por Aguilera Urquiza (2013, p. 64):

[...] esta terra torna-se fundamental para produção e reprodução da cultura de um povo, pois para eles, tudo que se relaciona com a estrutura social, ritual ou religiosa está intimamente relacionada ao território. A terra é, desta forma, um recurso sociocultural, mais que apenas um recurso da mãe natureza.

Diante desse quadro histórico e no contexto de todas essas transformações, segundo Duarte (2016),

O teko porã, ou seja, o modo de ser verdadeiro de um Guarani e Kaiowá, foi se modificando cada vez mais, pois o lugar em que vivíamos, o tekoha Pakurity, era cheio de indígenas e a possuía uma população bem numerosa, tanto da etnia Kaiowá, como a dos Guarani. Nós podíamos viver, falar e andar livremente segundo o nosso costume e tradição. Havia, também, uma casa de reza e vivíamos, o dia a dia, na maneira tekojoja (viver entre iguais) em toda comunidade, mostrando a importância da terra para a comunidade.

Nas décadas seguintes, as ações do governo em agrupar todos os indígenas do estado nas respectivas reservas intensificaram-se a todo custo e, diante desse quadro, a maior indignação, segundo Duarte, foi, principalmente, "a ação de esbulho contra os povos indígenas que contou com a ajuda do, até então, Serviço de Proteção aos Índios (SPI), visto que esse órgão tinha como objetivo a proteção dos povos indígenas".

Cabe lembrar que o processo de perda do território dos Kaiowá e Guarani se iniciou com os contratos de arrendamento de terras que beneficiaram a Companhia Matte Larangeira, já em fins do século XIX. A partir da decadência dessa empresa, décadas depois, intensifica-se o processo de ocupação e consequente esbulho das terras dos Kaiowá e Guarani para a colonização: derrubar as matas, formar pastos e ampliar a produção. Nesse cenário, abre-se, cada vez mais, espaço para os novos proprietários rurais, ou seja, colonos vindos de vários 
estados do Brasil a fim de se fixarem nestas terras. Com as terras sendo vendidas e com a fixação de novos proprietários, os indígenas são pressionados, cada vez mais, a irem para as reservas demarcadas ou a deixarem os seus espaços tradicionalmente ocupados e fugir para as áreas nos fundos das fazendas (EREMITES DE OLIVEIRA; PEREIRA, 2010, p. 112).

Podemos ver, nas palavras de Pereira, que houve poucos esforços para se reservar terras para os povos indígenas. $\mathrm{O}$ autor diz:

Quando se pensou em reservar terras para os índios, o destino inicial desses espaços era, via de regra, abrigar a população kaiowá que já vivia nesses locais. Entretanto, logo acabou prevalecendo a intenção de reunir nesses espaços a população de um grande número de comunidades kaiowá dispersas pelo território. (PEREIRA, 2006, p. 72).

E continua o mesmo antropólogo:

A população kaiowá resistiu de diversas formas, procurando manter a posse das terras que ocupava. Entretanto, a maior parte das famílias das comunidades que tiveram suas terras expropriadas pelas frentes de ocupação agropecuária gradativamente cedeu às pressões dos fazendeiros e dos funcionários do SPI e se recolheu às áreas de acomodação. (PEREIRA, 2006, p.72).

Após o esbulho de seus territórios, Duarte diz que os indígenas, sem ter o direito à permanência na terra, "começamos a andar pelas aldeias e reservas na região de Dourados". Diz ainda: "na época, como eu já era maduro, entendia muito bem que seguir para o lugar que nos mandavam ir, seja na aldeia de Dourados, Caarapó ou Amambai, o melhor era obedecer". Todo esse processo de levarem os indígenas, para as aldeias ou para as reservas era ordem dada pelos não indígenas, no caso, representantes do governo, o próprio SPI, e, muitas vezes, acompanhada de muita violência. Duarte continua: "Tudo isso acarretou na retirada do nosso território tradicional, o nosso tekoha. E isso aconteceu em várias aldeias e também no Pakurity".

E como relatado por vários autores ${ }^{6}$, os indígenas Kaiowá e Guarani do tekoha Pakurity não conseguiram viver livremente onde o estado os colocou, ou seja, nas reservas. "Não conseguimos viver, não da maneira do modo tradicional, ou seja, viver no tekojoja", segundo Duarte (2016).

\footnotetext{
${ }^{6}$ Podemos citar Brand (1997), Pereira (2006), Aguilera Urquiza (2013), entre outros.
} 
A partir do final da década de 1970 e principalmente dos anos 1980 em diante, é que se intensifica o movimento indígena e a mobilização política para obter do Estado o reconhecimento e a demarcação de parte do seu território tradicional como terras indígenas (CAVALCANTE, 2013, p. 24). Com o advento da Constituição Federal de 1988, a mobilização para a retomada do território tradicional ganha maior proporção no estado de Mato Grosso do Sul.

Assim, no dia 12 de agosto de 1988, os indígenas, liderado pelo senhor Duarte, seguem para o Pakurity e iniciam o processo de retomada do seu território tradicional. "Eu mesmo cortei o arame. São quase 28 anos e, até agora, no ano de 2016, nós não abandonamos ou saímos daqui. Estamos aqui cuidando da nossa terra" (DUARTE, 2016).

Para uma melhor compreensão da realidade das crianças indígenas do acampamento se faz necessário abordarmos, numa visão bibliográfica, como se dá o processo de demarcação das terras indígenas e trazer a atual situação da regulamentação do território tradicionalmente ocupado pelos indígenas da aldeia Pakurity.

\section{A DEMARCAÇÃO DAS TERRAS INDÍGENAS}

Antes de entendermos o processo de identificação, demarcação e homologação das Terras Indígenas, se faz necessário entender o que significa "Terra Indígena". Para Cavalcante (2013, p. 44) Terra Indígena, em uma abordagem geral, é "uma categoria jurídica, que, portanto, tem sua origem na definição de direitos territoriais indígenas". Já para a Fundação Nacional do Índio (FUNAI, s.d.[a]), significa:

Terra Indígena (TI) é uma porção do território nacional, de propriedade da União, habitada por um ou mais povos indígenas, por ele(s) utilizada para suas atividades produtivas, imprescindível à preservação dos recursos ambientais necessários a seu bem-estar e necessária à sua reprodução física e cultural, segundo seus usos, costumes e tradições. Trata-se de um tipo específico de posse, de natureza originária e coletiva, que não se confunde com o conceito civilista de propriedade privada.

Entendemos Terras Indígenas as terras tradicionalmente ocupadas e com o direito originário dos povos indígenas citadas no parágrafo primeiro do artigo 231 da Constituição Federal afirmando que: 
$\S 1$ - - São terras tradicionalmente ocupadas pelos índios as por eles habitadas em caráter permanente, as utilizadas para suas atividades produtivas, as imprescindíveis à preservação dos recursos ambientais necessários a seu bem-estar e as necessárias a sua reprodução física e cultural, segundo seus usos, costumes e tradições. (BRASIL, 1988).

A ocupação tradicional das terras pelos indígenas configura-se como um direito originário e, para isso, o procedimento administrativo de demarcação das terras indígenas se reveste de natureza declaratória, ou seja, a terra indígena não é criada por um ato constitutivo, mas reconhecida a partir de requisitos técnicos e legais de acordo com os termos da Constituição Federal de 1988. Outra coisa, por se tratar de um bem da União, as Terras Indígenas são inalienáveis, indisponíveis, e os direitos sobre elas são imprescritíveis.

Baseado nos termos da Legislação vigente, a FUNAI (s.d.[b]) classifica as Terras Indígenas nas seguintes modalidades:

Terras Indígenas Tradicionalmente Ocupadas: São as terras indígenas de que trata o art. 231 da Constituição Federal de 1988, direito originário dos povos indígenas, cujo processo de demarcação é disciplinado pelo Decreto ก.. 1775/96.

Reservas Indígenas: São terras doadas por terceiros, adquiridas ou desapropriadas pela União, que se destinam à posse permanente dos povos indígenas. São terras que também pertencem ao patrimônio da União, mas não se confundem com as terras de ocupação tradicional. Existem terras indígenas, no entanto, que foram reservadas pelos estados-membros, principalmente durante a primeira metade do século XX, que são reconhecidas como de ocupação tradicional.

Terras Dominiais: São as terras de propriedade das comunidades indígenas, havidas, por qualquer das formas de aquisição do domínio, nos termos da legislação civil.

Interditadas: São áreas interditadas pela FUNAI para proteção dos povos e grupos indígenas isolados, com o estabelecimento de restrição de ingresso e trânsito de terceiros na área. A interdição da área pode ser realizada concomitantemente ou não com o processo de demarcação, disciplinado pelo Decreto n.․ 1775/96.

Diante disso, significa dizer que os povos indígenas têm direito sobre seus territórios tradicionais e que têm seu conceito vinculado a norma constitucional. Para isso se faz necessário o reconhecimento, a demarcação e a homologação de suas terras. 
Para cumprir com o procedimento de demarcação de terra indígena, todo o processo está previsto para tramitar na via administrativa, através da regulamentação do Decreto n. 1775/96, iniciando-se na FUNAl e concluindo com expediente da presidência da república.

Segundo a FUNAI, tal Decreto é o meio administrativo utilizado pela União para identificar e sinalizar os limites do território tradicionalmente ocupados pelos povos indígenas.

Nos termos do mesmo Decreto, para a FUNAI, a regularização fundiária de terras indígenas tradicionalmente ocupadas compreende nove etapas (FUNAI, s.d.[c]), enquanto Cavalcante (2013, p. 49) estabelece cinco. São elas:

[...] seguir as etapas previstas no Decreto que são: 1a Identificação e Delimitação - da qual resulta um Relatório Circunstanciado de Identificação e Delimitação - RCID, que é o resultado do trabalho de um grupo técnico coordenado por um antropólogo de competência reconhecida e deve ser elaborado conforme a regulamentação da Portaria no 14, de 9/1/1996 do Ministério da Justiça. Aprovado pelo presidente da FUNAI, o RCID tem seu resumo publicado no Diário Oficial da União e no Diário Oficial do estado onde a terra indígena está localizada. Esta publicação caracteriza o reconhecimento pelo Estado brasileiro de que aquela determinada área é uma terra indígena. Após a análise das contestações administrativas, que podem ser apresentadas desde a constituição do grupo técnico até noventa dias após a publicação do resumo no Diário Oficial, encerra-se a primeira fase do processo de regularização fundiária. 2a Declaração - cabe ao ministro da justiça julgar o processo administrativo podendo declarar mediante portaria os limites da terra indígena e determinar a sua demarcação física, solicitar diligências, ou desaprovar a identificação mediante decisão fundamentada. 3a Demarcação física - após a publicação da portaria declaratória que reconhece a terra como de ocupação tradicional indígena e determina os seus limites, cabe à FUNAI realizar a

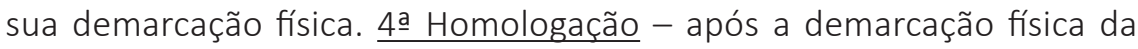
terra indígena, cabe ao presidente da república homologá-la mediante a edição de um decreto. 5 a Registro - após a homologação, a FUNAI deve registrar a terra indígena como propriedade da União no cartório local e na Secretaria de Patrimônio da União - SPU.

Durante todo esse processo administrativo, as Terras Indígenas vão passando por várias fases e, segundo a FUNAI, as fases do procedimento demarcatório das terras tradicionalmente ocupadas são: 
Em estudo: Realização dos estudos antropológicos, históricos, fundiários, cartográficos e ambientais, que fundamentam a identificação e a delimitação da terra indígena.

Delimitadas: Terras que tiveram os estudos aprovados pela Presidência da FUNAI, com a sua conclusão publicada no Diário Oficial da União e do Estado, e que se encontram na fase do contraditório administrativo e em análise pelo Ministério da Justiça, para decisão acerca da expedição de Portaria Declaratória da posse tradicional indígena.

Declaradas: Terras que obtiveram a expedição da Portaria Declaratória pelo Ministro da Justiça e estão autorizadas para serem demarcadas fisicamente, com a materialização dos marcos e georreferenciamento.

: Terras que possuem os seus limites materializados e georreferenciados, cuja demarcação administrativa foi homologada por decreto Presidencial.

Regularizadas: Terras que, após o decreto de homologação, foram registradas em Cartório em nome da União e na Secretaria do Patrimônio da União.

Interditadas: Áreas Interditadas, com restrições de uso e ingresso de terceiros, para a proteção de povos indígenas isolados.

Nesse contexto, é dever do Estado de demarcar as terras indígenas, considerando os espaços necessários ao modo de vida tradicional para os indígenas e, nesse caso, aos dos Kaiowá e Guarani, entendendo que o território é o espaço próprio de constituição e vivência identitária, principalmente se levado em conta que, para eles, essa relação é chamada de ñande reko1, quer dizer, "nosso jeito de ser".

\section{TEKOHA PAKURITY}

Os Indígenas que vivem em Pakurity são, em sua maioria, da etnia Kaiowá; apenas alguns são Guarani (Ñandeva). No Brasil são aproximadamente 51mil indígena da etnia Guarani e Kaiowá, sendo 31 mil Kaiowá, 13 mil Ñandeva e 7 mil Mbya; com exceção do último, localizados principalmente em Mato Grosso do Sul'.

O acampamento Pakurity está localizado próximo da BR 463, a 20 km do perímetro urbano de Dourados. Contando com aproximadamente 15 barracos de

\footnotetext{
${ }^{7}$ Fonte: FUNASA e FUNAI (2008). Disponível em: <http://pib.socioambiental.org/pt/povo/ guarani-kaiowa/554>.
} 
lona que se espalham ao longo de um canal de água, segundo o senhor Duarte (2014), líder indígena, há no acampamento 87 pessoas distribuídas em 10 famílias e mais 80 crianças.

Como consta na história dos povos indígenas do estado, a comunidade do Pakurity também vivencia o impasse territorial, situação que os levou a viver à margem da BR 463, enquanto não podem conseguir de volta sua terra.

Essa tentativa de sair das margens de rodovias e realizar "retomadas", ou seja, tentativas de reocupar o direito as áreas que consideram suas terras tradicionais é comentada por Pereira (2010, p. 118):

Às iniciativas de vários líderes indígenas de tentarem reagrupar suas comunidades com o fim de reocupar parte dos territórios perdidos para a ocupação agropastoril. Tais tentativas são percebidas como necessárias para recuperar as condições necessárias à reprodução física e cultural de suas comunidades. Isto requer o empenho dos líderes no reagrupamento dos parentes e na atualização de formas de sociabilidade parental, tornando possível a atualização das comunidades políticas. Apresentar- se como comunidade política é o primeiro passo para novamente reivindicarem uma base territorial.

Atualmente a aldeia Pakurity se encontra próxima a uma mata ciliar, vivendo em alguns poucos hectares, dos 15.500 ha reivindicado, ou seja, a comunidade se encontra em uma mínima parte de propriedade maior. Possui duas nascentes de água para a sobrevivência e para a utilização dos afazeres diários dos indígenas. Mesmo assim, vivendo em parte do seu tekoha, trata-se de uma comunidade em situação de acampamento, cercada de situações de conflitos e provisoriedade.

As condições de vida no Pakurity não diferem da realidade de outras comunidades, em situação de acampamento. As dificuldades enfrentadas cotidianamente são inúmeras. Crespe (2009 , p. 61) acrescenta:

Como o lugar não oferece as condições necessárias para a sobrevivência torna-se necessário estabelecer alternativas e estratégias que permitam a permanência deles ali, por isso, a maioria dos homens precisam trabalhar como diaristas nas roças vizinhas ao acampamento. Como o acampamento não oferece espaço para plantar, nem água para consumo, o recurso encontrado é seguir até à mata, que fica do lado de dentro da propriedade, para ter acesso à água, lenha e remédios. 
Tratar da atual situação da regulamentação e demarcação das terras da aldeia Pakurity é assunto muito delicado e complicado, principalmente por se tratar de mais um dos casos que está inserido no contexto dos conflitos fundiários que ocorrem em Mato Grosso do Sul, fruto de fatos históricos ou por ações e omissão do Estado brasileiro. Atualmente são mais de 40 acampamentos que estão, ou na beira da estrada, ou em pequenas parcelas de seu território tradicional (como é o caso do Pakurity), ou ainda, tentando mais uma "retomada" de seu território tradicional.

No site na FUNAl e do Ministério Público, não consta nenhuma informação quanto à atual situação desse processo da aldeia Pakurity. Sabemos que, em 12 de novembro de 2007, foi assinado o Termo de Ação e Conduta (TAC) com a finalidade de constituir Grupos Técnicos com vistas à identificação e delimitação de sete Áreas Indígenas. As Terras Indígenas estão divididas em grandes áreas que abrangem várias aldeias. A aldeia Pakurity está inserida na Área Indígena Douradopegua. O GT seria constituído por especialistas, coordenado por um antropólogo, que deveria elaborar os relatórios de identificação das Terras Indígenas. No caso do Pakurity, até o momento, ainda não houve a finalização de todo esse processo.

Sem o relatório de identificação finalizado, a fonte de dados para a pesquisa sobre quais os limites que abrange o território do Pakurity volta-se para os relatos do Sr. Bonifácio Duarte. Ele afirma que conhece muito bem a área reivindicada como sendo o território de posse tradicional de seu povo. "Tenho gravado em minha cabeça, posso mostrar em todos os caminhos que usamos na nossa vida do dia a dia. Caminhos que fazem parte na nossa caça, pesca e contato com outros parentes" (DUARTE, 2016).

Segundo ele, "o território vai da cerca próxima ao Yvyjumirim até o Manguruju e do Pirity ao Ajacareta". Essas marcações e outras mais específicas o Sr. Bonifácio Duarte desenhou em um papel (Figura 1). Segundo ele, "tal figura foi produzida pela comunidade para não permitir o esquecimento de toda a área que corresponde ao território tradicional do Pakurity". Para Duarte "a área proporcionava aos antigos a liberdade de viver e andar livremente em toda a sua extensão".

Observando ainda a Figura podemos destacar que o tekoha Pakurity envolve ambos os lados da BR 463. Do lado oposto em que encontramos atualmente a comunidade, está a região do Pirity (n. 2 na Figura 1). Recebe esse nome porque, 
segundo Duarte, "os antigos saáam do rio Dourados e caminhavam até o Pirity para buscar uma espécie de semente que os mesmos utilizavam para colocar dentro do chocalho a fim de produzir o som". Na parte superior esquerda, há um cemitério no qual está enterrado o seu pai, antigo Cacique. Segundo Bonifácio, "no cemitério havia 18 corpos indígenas, mas hoje não encontramos nenhum, pois o fazendeiro pagou propina para destruí-lo" (n. 1 na Figura 1). Observamos que pacuri é uma espécie de àrvore com um fruto comestível, cujo sumo e casca servem para curar ferida, e a madeira pode-se utilizar para confecção de móveis, também é encontrado na região e está representado no lado inferior esquerdo do desenho.

Na parte inferior direita, encontramos a localização da área da atual permanência dos indígenas do Pakurity (n. 3 na Figura 1), devidamente sinalizada.

Ainda na Figura 1, podemos verificar, na parte inferior do canto esquerdo, a assinatura (n. 4 na Figura 1) do presidente da FUNAI, Mércio Pereira Gomes (2003 a 2007). O relato menciona que, em sua visita, ele pôde verificar a localização e permanência da comunidade na aldeia Pakurity. O senhor Bonifácio Duarte afirma que "Mércio nos encontrou nesse mesmo local, lugar onde fizemos a primeira retomada física e aqui permanecemos até hoje". De maneira bem geral, segundo o relato do líder indígena Bonifácio Duarte toda a extensão da aldeia Pakurity abrange desde o rio Dourados até o local em que a comunidade se encontra atualmente, compreendendo os dois lados da BR463. 


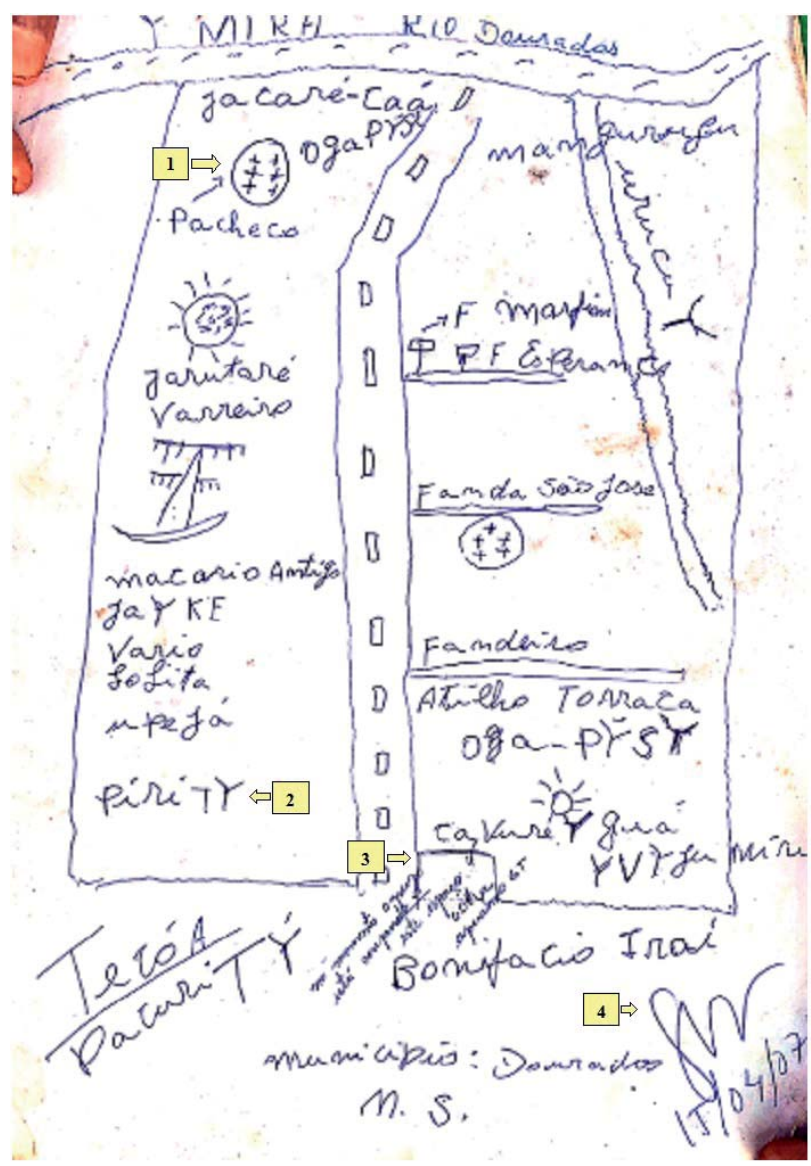

Figura 1 - Pakurity- desenho produzido pela comunidade LEGENDA: 1. Cemitério onde foi enterrado o pai de Bonifácio o Cacique Duarte; 2. Região do Pirity; 3. Local onde se encontra a comunidade indígena do Pakurity; 4. Assinatura do presidente da Funai Mércio Pereira Gomes.

Para o líder Bonifácio Duarte, retornar a viver em seu tekoha representa viver e praticar a cultura do povo. É viver e cultivar o tekojoja que quer dizer:

É uma vida de igualdade e, para nós cultivarmos o tekojoja, é primordial retomarmos a nossa vida tradicional, voltar a nossa terra. Retornarmos em todo o nosso tekoha Pakurity, nosso território tradicional. Dessa forma estaremos vivendo igualmente aos nossos antigos em nosso tekoha, pois o modo de viver está gravado na memória de cada um, desde as criança até os velhos, ou seja, dos velhos que transmitem para as nossas crianças. E nesse ciclo o nosso tekojoja nunca acaba, mas passa de geração em geração. (DUARTE, 2016). 
Diante dessa realidade enfrentada pelos indígenas da aldeia Pakurity, é que se faz de suma importância mostrar um pouco mais sobre como não apenas os adultos ou a liderança entende a situação de acampamento, mas também como as crianças têm enfrentado tal realidade.

\section{RESULTADOS ATÉ AGORA OBTIDOS - AS CRIANÇAS DA ALDEIA PAKURITY}

Falar em criança, usualmente, é estabelecer pontes entre o presente e o futuro, isso entendido como se a criança existisse hoje para ser o amanhã, como se todo esse processo de crescimento fosse um livro em branco e que pouco ou quase nada influenciasse na realidade em que está inserida. Essa é a ideia de muitos quando o assunto é abordar o modo de ser e viver das crianças, mesmo quando não levamos em conta ou não conhecemos o seu papel no grupo social ao qual pertence. O senso comum dita que as crianças são meras depositárias do conhecimento.

Para Cohn (2005, p. 28), no entanto,

A criança atuante é aquela que tem um papel ativo na constituição das relações sociais em que se engaja, não sendo, portanto, passiva na incorporação de papéis e comportamentos sociais. Reconhecê-la é assumir que ela não é um "adulto em miniatura", ou alguém que treina para a vida adulta. É entender que, onde quer que esteja, ela interage ativamente com os adultos e as outras crianças, com o mundo, sendo parte importante na consolidação dos papéis que assume e de suas relações.

Com o mesmo ponto de vista de Cohn (2005), entendemos que a criança possui um papel ativo na construção da realidade da comunidade indígena. Assim, afirmamos que as crianças são parte integrante e que constroem suas relações estabelecidas dentro de sua sociedade e também autoras na construção de sua identidade. Dessa maneira, assumimos que a criança indígena tem um papel ativo e de fundamental importância na construção da cultura. São agentes que constroem suas relações e Ihes dão sentido. São atores sociais, produtores ativamente inseridos em sua cultura, participantes do ambiente e da vida diária da comunidade. Em tudo as consideramos como portadoras e fonte de saber.

Diante do saber da criança, salientamos que, para compreendermos o que é a criança, como vivem e pensam é necessário: 
Desvencilharmos das imagens preconcebidas e abordar esse universo e essa realidade tentando entender o que há neles, e não o que esperamos que nos ofereçam. Precisamos nos fazer capazes de entender a criança e seu mundo a partir do seu próprio ponto de vista. (COHN, 2005, p. 8).

Nesse contexto, nos perguntamos: como fazer para se ouvir a voz das crianças Kaiowá? Manuel Jacinto Sarmento traz a seguinte reflexão:

No entanto, o paradoxo maior da expressão "ouvir a voz das crianças" reside não apenas no facto de que ouvir não significa necessariamente escutar, mas no facto de que essa "voz" se exprime frequentemente no silencio, encontra canais e meios de comunicação que se colocam fora da expressão verbal, sendo, aliás, frequentemente infrutífero os esforços por configurar no interior das palavras infantis aquilo que é o sentido das vontades e das ideias das crianças. Mas essas ideias e vontades fazem-se "ouvir" nas múltiplas outras linguagens com que as crianças comunicam. Ouvir a voz é, assim, mais do que a expressão literal de um acto de auscultação verbal (que, alias, não deixa também de ser), uma metonímia que remete para um sentindo mais geral de comunicação dialógica com as crianças, colhendo as suas diversificadas formas de expressão. (SARMENTO, 2011, p. 28).

O autor acrescenta que "o desenho infantil insere-se entre as mais importantes formas de expressão simbólica das crianças". Dessa maneira, escolhemos a técnica de desenhos como forma de expressar a percepção das crianças indígenas da aldeia Pakurity em relação ao seu território, lembrando que elas se encontram em situação de acampamento, o que pode modificar a compreensão da realidade de suas vidas no dia a dia.

Foram 25 desenhos confeccionados por onze crianças indígenas da idade de 6 a 15 anos da aldeia Pakurity. Para a realização metodológica da técnica com desenhos, reunimos as crianças na área de reuniões e entregamos papel branco e lápis coloridos sortidos a cada uma, com o pedido de que desenhassem, conforme a sua maneira (Figura 2), o que achavam da vida no acampamento, ou seja, que desenhassem seu cotidiano. Sentadas no chão, nos bancos ou em pneus abandonados e até mesmo deitadas, cada criança fez o seu desenho durante um certo tempo. Cabe salientar que cada folha equivale a um desenho feito por uma criança indígena, pois houve a participação de alguns adultos, mas os desenhos produzidos por eles não foram considerados para o estudo em tela. 


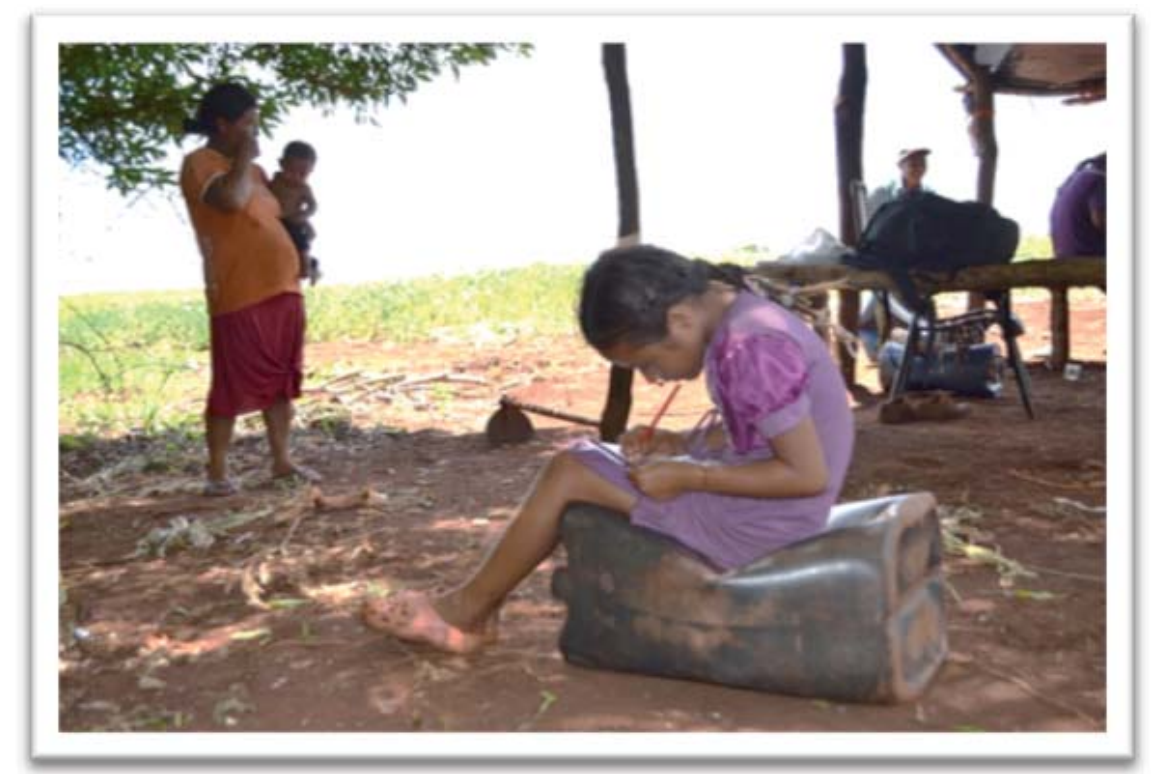

Figura 2- Crianças do Pakurity desenhando Fonte: Arquivos da pesquisa (2014).

Após a atividade do desenho das crianças, continuamos entre elas na comunidade, visitando seus espaços de convivência, recreação e de relações sociais.

Para a análise dos desenhos, utilizamos a classificação destes em seis grupos, conforme os seguintes temas: 1. Flora- Desenhos referentes à vida vegetal; 2. Fauna - Temas referentes à vida animal; 3. Terra - Desenhos referentes a terra, ou relações com o ambiente; 4. Lagos - Temas referentes a lagos ou rios; 5 . Temas Tradicionais - Desenhos referentes a objetos de uso tradicional da cultural Kaiowá e Guarani do Pakurity e 6. Outros Temas - aqueles que não se apresentam na cultura Kaiowá e Guarani do Pakurity (elementos externos à sua cultura tradicional).

Os desenhos, uma vez recolhidos, foram separados nas temáticas apresentadas para a análise dos seis grupos.

No grupo temático 1. Flora- Elementos referentes à vida vegetal - apresentam temas referentes a árvores, flores e plantas. São 68\% dos desenhos realizados pelas crianças indígenas que apresentam o tema de árvores, montanhas, plantas, flores e gramas. Dos 25 desenhos realizados pelas crianças, 17 deles continham algum desses objetos. 
No grupo do tema 2. Fauna - Elementos referentes à vida animal Encontramos a presença desse tema em $68 \%$ dos desenhos, os quais apresentavam alguma espécie de animal. Os animais contidos nos desenhos são: pássaros, tatu, cobra, peixes, cachorro, cavalo, touro e onça.

Elementos referentes a terra (Grupo 3) são encontrados em 11 desenhos. Contamos como tema referente a terra toda imagem que delimita o espaço físico (chão) no desenho, como exemplo, montanhas, caminhos, estrada ou uma determinada região cercada. Caso o desenho apresente uma casa tradicional, mas sem a delimitação do solo, não foi considerado. Se fossemos somar todos os desenhos que têm a possibilidade de uma representação do solo ou uso da terra, apenas dois desenhos do total geral não se encaixariam nesse grupo, pois esses desenhos apresentam apenas objetos tradicionais (diadema indígena, arco, flecha e maracá). Nesse sentido, foram $44 \%$ dos desenhos que apresentam, de forma expressa, algum tipo de objeto referente a terra.

Desenhos referentes a lagos ou rios (Grupo 4) foram expressados em 20\% dos desenhos, sendo que, dos 25 desenhos realizados, quatro deles continham objetos relacionados a lagos e um relacionado a um rio.

Elementos como casa tradicional, espécie de diadema indígena, arco, flecha, maracá, fogueira, cacique e até um pajé estiveram presentes em $64 \%$ dos desenhos do grupo 5 em que se refere aos desenhos que apresentaram objetos pertencentes ao cotidiano da vida tradicional Kaiowá e Guarani - Pakurity (Grupo 5).

No grupo 6. Outros Temas, obtivemos $20 \%$ dos desenhos que apresentaram figuras que não estão inseridos no dia a dia das crianças Kaiowá do acampamento Pakurity. São cinco desenhos, sendo que eles representam a imagem de casas de alvenaria e de uma escola (imagens estereotipadas). Esses objetos por mais que remetam à cultura não indígena, eles estão cada vez mais presentes e próximos do seu cotidiano. Cabe a indagação de que até que ponto a casa de alvenaria e a escola ainda não fazem parte da cultura das crianças da aldeia Pakurity?

Cabe ressaltar que o maior índice apresentado nos desenhos faz referência aos grupo temáticoss 1 e 2 (presentes em 17 desenhos) seguido do grupo 5 (presentes em 16 desenhos), ou seja, representam a Flora (68\%), fauna (68\%) e Temas Tradicionais (64\%) os quais interligados fazem referência ao modo de viver em relação com a terra, tema segue em quarto lugar com 44\% e presente em 11 
dos desenhos. Isso demonstra que os desenhos das crianças reproduzem o teko porã, ou seja, o modo de viver/ser de um Kaiowá e Guarani.

Para a melhor ilustração da classificação e dos resultados aqui apresentados, selecionamos três desenhos para que possamos visualizar alguns temas utilizados pelas crianças da aldeia Pakurity (Figuras 3 a 5) e que representam seu cotidiano, a relação com o meio ambiente e a cultura tradicional.

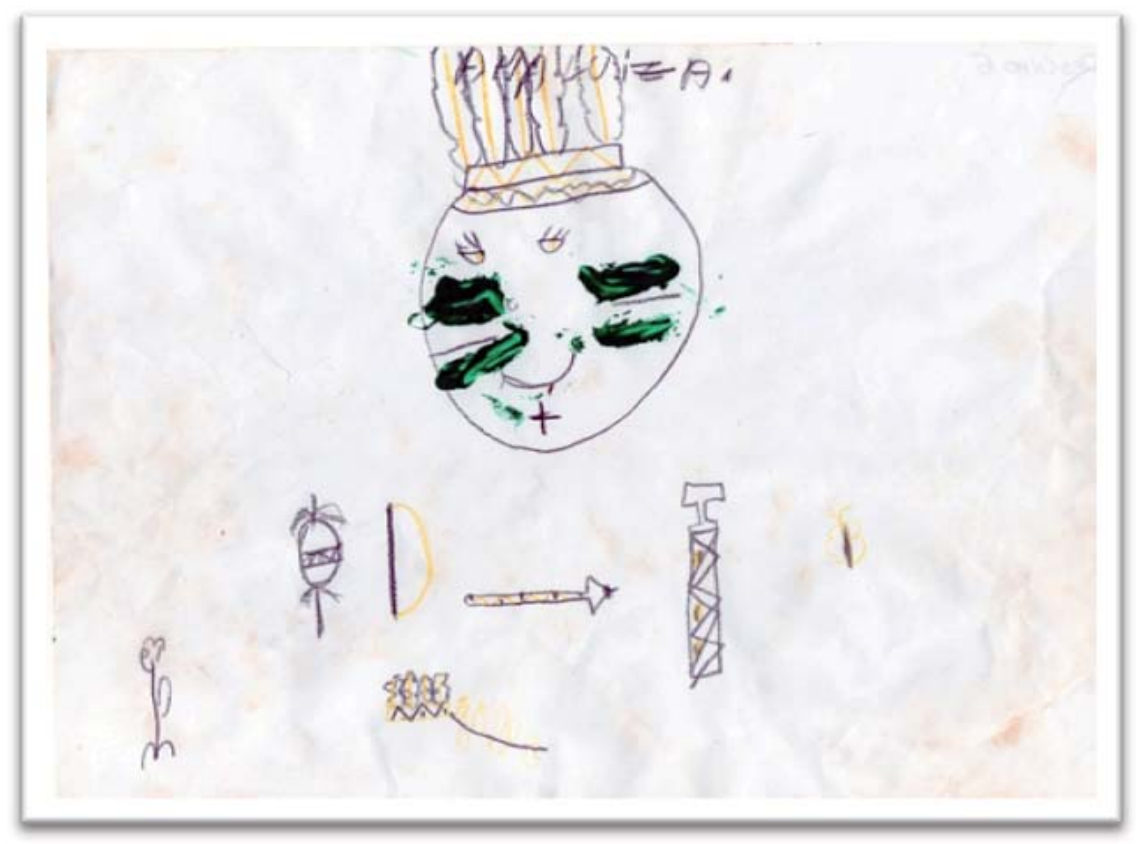

Figura 3 - Desenho classificado nos grupos 1, 2 e 5 Fonte: Arquivo da pesquisa (2014).

A figura 3 mostra um desenho que contém uma pequena "flor" no camto direito e mais duas quase ao centro e parte inferior da folha, as quais são representadas no Grupo 1 - Flora. Os demais temas apresentados nesse desenho nos remetem ao Grupo 5- Temas tradicionais. Em sua maioria, notamos que os objetos são a tipificação de uma indígena com cocar de penas, um Maracá, arco e flecha. Outro elemento que quase passa por imperceptível é uma pequena borboleta no lado direito da folha. O desenho apresentado traz imagens dos Grupos 1, 2 e 5 (Flora, Fauna e elementos da cultura Tradicional). 


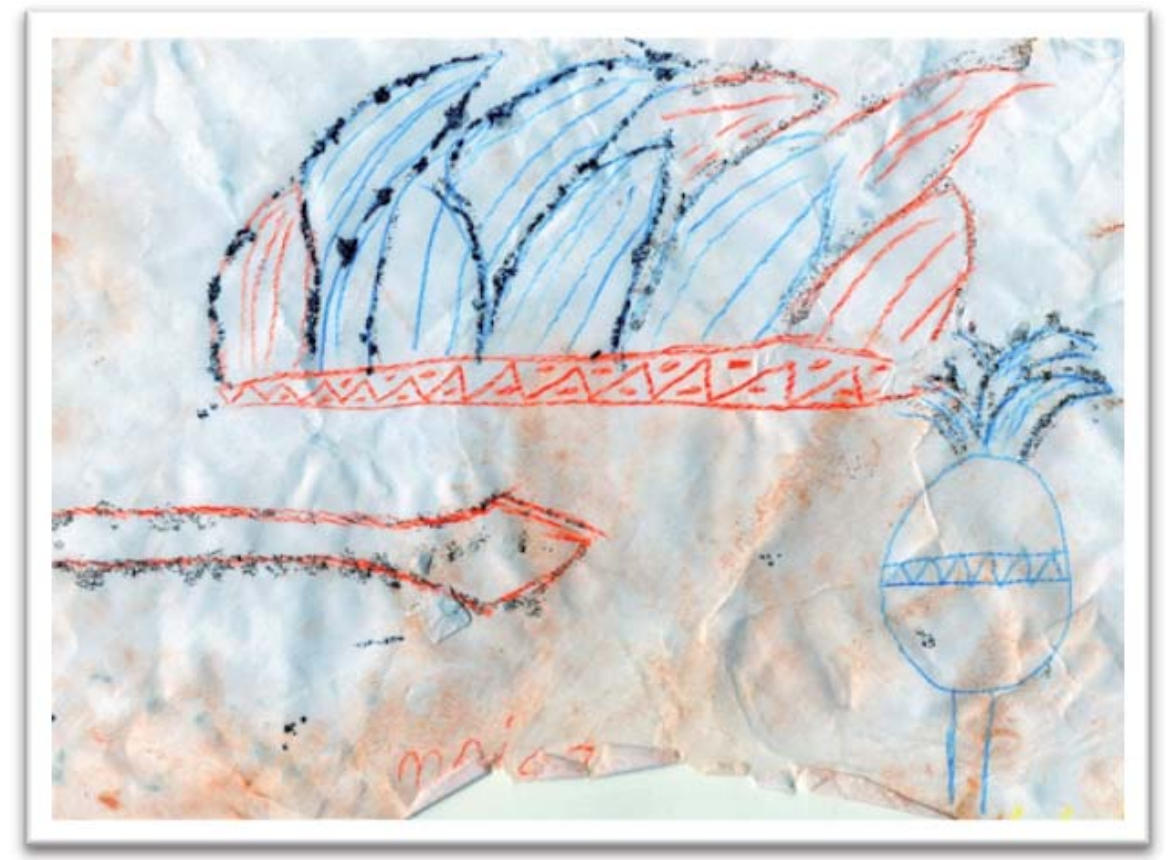

Figura 4 - Desenho classificado no grupo 5

Fonte: Arquivo da pesquisa (2014).

A Figura 04 contém apenas objetos de uso tradicional (Grupo 5) da cultura Kaiowá e Guarani do Pakurity. Não cabe aqui a discussão se o cocar (jeguaká) utilizado pelos Kaiowá e Guarani são confeccionados com penas ou com pequenos penachos de lã, apenas queremos trazer o significado de um objeto de uso tradiconal para uma crinaça indígena através do desenho. 


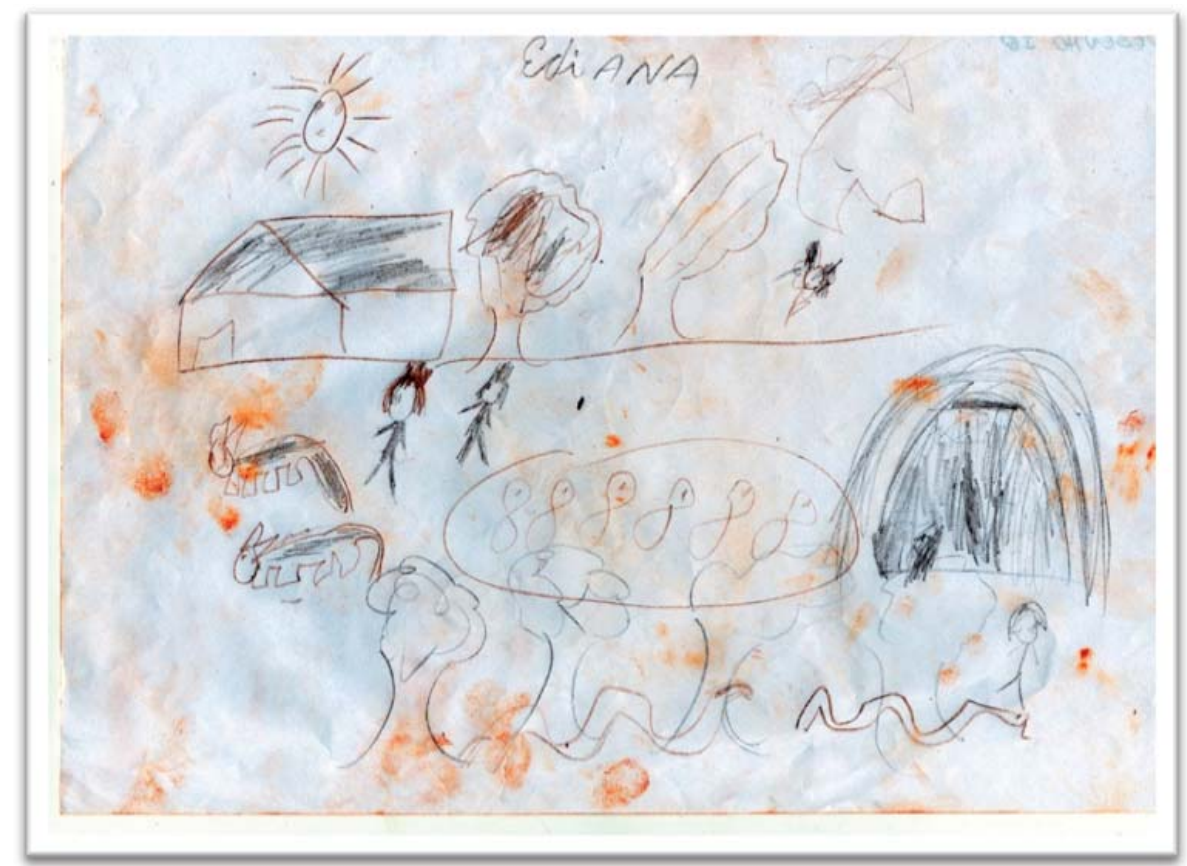

Figura 5 - Desenho classificado em vários grupos temáticos tFonte: Arquivo da pesquisa (2014).

Na apresentação da Figura 5, apresenta-se significativa quantidade e variedade de temas contidos no desenho. Contém temas da flora (árvores), da fauna (tatu, cobra e "cachorro"), da terra (linha horizontal abaixo da casa que nos remete à existência de um solo), um lago, uma casa tradicional e uma casa de alvenaria. Os seis grupos mencionados são apresentados nesse desenho pela criança indígena.

As manifestações específicas na forma de desenho, por parte das crianças da comunidade do Pakurity, demonstram a intrínseca relação entre estas e seu território, assim como em relação às manifestações culturais tradicionais.

\section{CONCLUSÃO}

Conhecedores do Artigo 231 da Constituição Federal de 1988, os autores deste trabalho vêm, mais uma vez, salientar o direito que os povos indígenas possuem de terem costumes, línguas, religiões e organizações sociais distintas daquelas válidas à sociedade nacional, mesmo conhecedores da situação histórica 
dos Kaiowá e Guarani. Neste caso, referimo-nos ao dos que se encontram no sul do estado de Mato Grosso do Sul, cuja história é caracterizada pela negligência em muitos de seus direitos, principalmente na perda de seus territórios.

A partir desse contexto é que a presente pesquisa procurará estudar com maior profundidade e descrever as condições em que vivem os indígenas, em sua particularidade as crianças, que se encontram no acampamento Pakurity, bem como compreender quem são esses sujeitos Kaiowá e Guarani e como percebem e representam a situação de acampamento em que estão submetidos. Tanto porque, quando as crianças indígenas do acampamento Pakurity, ao serem provocadas acerca da sua realidade e relação com o território e as tradições, respondem através de desenhos realizados no primeiro trabalho de campo que referenciam o modo de viver do dia a dia e que envolvem elementos da mata, os animais, da natureza e alguns de uso tradicional, a exemplo da casa tradicional, a fogueira, o maracá, o arco e flecha, entre outros. Os desenhos e a análise aqui apresentada nos levam a concluir, de início, que as crianças entendem que o território é imprescindível à preservação e à reprodução de sua cultura. As crianças possuem uma profunda relação física, afetiva e simbólica com a terra e com os elementos de sua cultura.

Essa constatação choca-se com a realidade atual das comunidades Kaiowá e Guarani, em especial, aquelas em situação de acampamento, realidade de extrema vulnerabilidade e desrespeito aos direitos humanos básicos dessa população. Essa realidade histórica de perda do território tradicional e de suas consequências segue comprometendo o modo de ser tradicional desse povo (ñande reko), assim como compromete o crescimento saudável dessas crianças e todos os direitos inerentes ao ordenamento jurídico nacional e internacional.

O texto reflete, assim, os resultados parciais de uma pesquisa em andamento, acerca das crianças da comunidade Kaiowá e Guarani do PAKURITY, relacionando a situação de acampamento, com a situação das crianças indígenas, através da pesquisa de campo e da técnica do desenho livre e do desenho estimulado por temas do seu cotidiano. 


\section{REFERÊNCIAS}

AGUILERA URQUIZA, A. H (Org.). Cultura e história dos povos indígenas em Mato Grosso do Sul. Campo Grande, MS: Ed. UFMS, 2013. 334p. BRAND, Antônio. O impacto da perda da terra sobre a tradição kaiowá/guarani: os difíceis caminhos da Palavra. 1997. Tese (Doutorado em História)- Pontifícia Universidade Católica do Rio Grande do Sul (PUC-RS), Porto Alegre, 1997.

. O confinamento e seu impacto sobre os Pãi/Kaiowá. 1993. Dissertação (Mestrado em História) - Pontifícia Universidade Católica do Rio Grande do Sul (PUC-RS), Porto Alegre, 1993.

BRASIL. Constituição da República Federativa do Brasil. Brasília, DF, 1988. Disponível em: <http://www.planalto.gov.br/ccivil_03/constituicao/constituicaocompilado.htm>.

CAVALCANTE, Thiago Leandro Vieira. Colonialismo, território e territorialidade: a luta pela terra dos Guarani e Kaiowá em Mato Grosso do Sul. 2013. Tese (Doutorado em História) - Faculdade de Ciência e Letras, Universidade Estadual Paulista (UNESP), Assis, SP, 2013. . Relatório Violência contra os povos indígenas no Brasil. Brasília, 2014. Disponível em: <http://www.cimi.org.br/pub/MS/Viol_MS_2003_2010.pdf>. Acesso em: 9 jun. 2016.

. As violências contra os povos indígenas em Mato Grosso do Sul. Brasília, 2010. Disponível em: http://www.cimi.org.br/pub/MS/Viol_MS_2003_2010.pdf. Acesso em: 9 jun. 2016.

COHN, Clarice. Antropologia da criança. Rio de Janeiro: Jorge Zahar, 2005.

CRESPE, Aline Castilho. Acampamentos indígenas e ocupações: novas modalidades de organização e territorialização entre os Guarani e Kaiowa no município de Dourados- MS: (1990-2009). 2009. Dissertação (Mestrado em História) - Universidade Federal da Grande Dourados (UFGD), Dourados, 2009.

CUNHA, Manuela Carneiro da (Org.). História dos índios no Brasil. São Paulo: Companhia das Letras, 1992

DUARTE, Bonifácio Reginaldo. Entrevista [22 jan. 2014]. Entrevistador: Sônia Rocha Lucas. Rio Brilhante (acampamento Pakurity), 2014. Anotações em caderno de campo. Entrevista concedida no âmbito do projeto de iniciação científica (PIBC/CNPq) desenvolvido por Sônia Rocha Lucas junto à Universidade Federal de Mato Grosso do Sul.

. Entrevista [16 abril. 2016]. Entrevistador: Sônia Rocha Lucas. Dourados (acampamento Pakurity), 2016. Anotações em caderno de campo e filmagem. Entrevista concedida no âmbito do projeto de mestrado (Antropologia- UFGD). 
ELOY AMADO, L. H. Terra indígena e legislação indigenista no Brasil. Cadernos de Estudos Culturais, Campo Grande, MS, v. 7, n. 13, p. 65-84, 2015

EREMITES DE OLIVEIRA, J.; PEREIRA, L. M. Reconhecimento de territórios indígenas e quilombolas em Mato Grosso do Sul: desafios para a antropologia social e a arqueologia em ambientes colonialistas. In: AGUIAR, Rodrigo Luiz S. et al. (Org.). Arqueologia, etnologia e etno-história em Iberoamérica: fronteiras, cosmologia e antropologia em aplicação. Dourados, MS: Editora UFGD, 2010. p. 185-208.

FUNDAÇÃO NACIONAL DO ÍNDIO (FUNAI). Terras indígenas: o que é? (s.d.[a]). Disponível em: <http://www.funai.gov.br/index.php/2014-02-07-13-24-32>. Acesso em: 18 out. 2015

. Modalidades de terras indígenas. (s.d.[b]). Disponível em: <http://www.funai. gov.br/index.php/indios-no-brasil/terras-indigenas>. Acesso em: 18 out. 2015.

. Entenda o processo de demarcação. (s.d.[c]). Disponível em: <http://www.funai. gov.br/index.php/2014-02-07-13-24-53>.

INSTITUTO BRASILEIRO DE GEOGRAFIA E ESTATÍSTICAS (IBGE). Censo Demográfico 2010. Disponível em: <https://www.ibge.gov.br/estatisticas-novoportal/sociais/saude/9662-censo-demografico-2010.html>.

PEREIRA, Levi Marques. Demarcação de terras kaiowa e guarani em MS: ocupação tradicional, reordenamentos organizacionais e gestão territorial. Tellus, Campo Grande, MS, ano 10, n. 18, p. 115-37, jan./jun. 2010.

. Mobilidade de processo e processo de territorialização entre os Guarani atuais. História em Reflexão, Dourados, MS, v, 1, n. 1, p. 1-33, jan./jun. 2007.

. Assentamentos e formas organizacionais dos Kaiowá atuais: o caso dos "índios de Corredor". Tellus, Campo Grande, MS, ano 6, n. 10, p. 69-81, abr. 2006.

. No mundo dos parentes: a socialização das crianças adotadas entre os Kaiowá. In: SILVA, A. L. S.; NUNES, A. (Org.). Crianças indígenas: ensaios antropológicos. São Paulo: Global, 2002.

SARMENTO, Manuel Jacinto. Conhecer a infância: os desenhos das crianças como produções simbólicas. In: MARTINS FILHO, Altino José; PRADO, Patrícia Dias (Org.). Das pesquisas com crianças à complexidade da infância. Campinas, SP: Autores Associados, 2011. 


\section{Sobre os autores:}

Sônia Rocha Lucas: Mestre em Antropologia (PPGAnt/UFGD). Graduada em Ciências Sociais da UFMS, participa do Grupo de Pesquisa Antropologia, Direitos Humanos e povos Tradicionais. Supervisora da ação Saberes Indígenas na Escola (MEC/SECADI). Área de Antropologia e Direitos Humanos. Participa do grupo de Pesquisa (CNPq) Antropologia, Direitos Humanos e Povos Tradicionais. E-mail: soninhalucas@gmail.com

Antonio Hilario Aguilera Urquiza: Mestre em Educação (Educação Indígena) pela Universidade Federal de Mato Grosso (1999); master em educação (tecnologias de la educación - 2001) e doutorado em Antropologia pela Universidade de Salamanca-Espanha (2006). Cursa Pós-doutorado no Programa de Estudios Posdoctorales- UNTREF (Argentina)- Projeto: Diálogo de conhecimentos e educação superior no Brasil. Espaço estratégico de construção da autodeterminação dos povos indígenas (Diretor: Dr. Daniel Mato). Professor Adjunto da UFMS, e da Pós-graduação em Antropologia Social (UFMS), assim como da Pós-graduação em Direitos Humanos (FADIR/UFMS). Professor colaborador dos Programas de Pós-graduação em Antropologia (PPGAnt) da UFGD e da Pós-graduação em Educação da UCDB. Pesquisador do CNPq. Bolsista Produtividade (PQ2). E-mail: hilarioaguilera@gmail.com

Recebido em 14 de junho de 2017

Aprovado para publicação em 11 de setembro de 2017 
